\title{
Seek Help from Teachers or Fight Back? Student Perceptions of Teachers' Actions during Conflicts and Responses to Peer Victimization
}

\author{
Mario J. Aceves · Stephen P. Hinshaw • \\ Rodolfo Mendoza-Denton · Elizabeth Page-Gould
}

Received: 3 May 2009/Accepted: 4 August 2009/Published online: 19 August 2009

(C) The Author(s) 2009. This article is published with open access at Springerlink.com

\begin{abstract}
Previous research has shown that teachers' actions when addressing conflict on school grounds can shape adolescent perceptions regarding how well the school manages victimization. Our objective in this study was to determine how these perceptions influenced the likelihood that adolescent students would react to victimization scenarios by either seeking help from school authority or physically fighting back. Vignettes describing two events of victimization were administered to 148 ethnic minority adolescents (Latino, African American, and Asian backgrounds; $49 \%$ female) attending an urban high school with high rates of conflict. Positive perceptions of teachers' actions during conflicts-assessed via a questionnaire tapping how teachers manage student conflicts both generally and in a specific instance of strife-predicted a greater willingness to seek help from school authority, which in turn negatively predicted self-reported aggressive responses to the victimization scenarios. Path analysis established the viability of this indirect effect model, even when we controlled for sex, beliefs about the acceptability of aggression, and previous levels of reactive aggression. Adolescents' perceptions of teachers' actions during conflicts are discussed in relation to social
\end{abstract}

M. J. Aceves $(\bowtie) \cdot$ S. P. Hinshaw - R. Mendoza-Denton

University of California, Berkeley, CA, USA

e-mail: mja@berkeley.edu

S. P. Hinshaw

e-mail: hinshaw@berkeley.edu

R. Mendoza-Denton

e-mail: rmd@berkeley.edu

E. Page-Gould

University of Toronto Scarborough, Scarborough, ON, Canada

e-mail: elizabeth.page-gould@utsc.utoronto.ca information processing models, improving student-teacher relations, and decreasing aggression at schools.

Keywords Victimization - Student-teacher relationships . Conflict resolution · Reactive aggression · Adolescence

\section{Introduction}

When student conflicts occur on school grounds, teachers have the opportunity to intervene and assist in achieving conflict resolution. These interventions may be especially meaningful for victimized students who are unable to defend themselves against aggressive peers (Bernstein and Watson 1997). Students involved in such hostile interactions, as well as those who witness such events, begin to take note of how teachers' respond and act during conflicts (Rigby and Bagshaw 2003). Although student perceptions of teachers' abilities to address conflicts are relatively understudied, some research suggests that such perceptions are important predictors of students' attitudes towards teachers and may also be related to student behavior in response to provocation or victimization (e.g., Herzberger and Hall 1993; Rigby and Bagshaw 2003; Rogers and Tisak 1996). Additional research in this area is imperative for understanding how perceptions of teachers influence adolescent coping responses to conflicts that occur on school grounds.

Students can respond to victimization in various ways (e.g., ignoring the problem, turning to friends, violently retaliating). One option is turning to teachers to address school conflicts, though it is unclear what factors precede an adolescent's decision to seek help from teachers when conflicts arise. In this article, we examine how student perceptions of teachers' actions during conflicts form the 
basis for expectations regarding how well school authorities can handle issues related to victimization and violence. We also explore links between these student perceptions and reactively aggressive responses to victimization from a social information processing perspective (Crick and Dodge 1994; Fontaine and Dodge 2006). Broadly, we propose that students who perceive teachers' actions during conflicts as positive are more likely to turn to school authority (e.g., a teacher) when victimized, thus minimizing the probability of a reactively aggressive response.

Rigby and Bagshaw (2003) have previously examined student perceptions of teachers' actions during conflicts involving bullying and victimization. In two studies of Australian adolescents, the authors found that $51.4 \%$ of boys and $43 \%$ of girls were unconfident in teachers' abilities to address bullying. These students judged teachers and their actions during conflicts on dimensions of fairness, effectiveness (i.e., skills), and helpfulness-which, along with procedural justice and outcome satisfaction variables, predict attitudes towards authority (Lind and Tyler 1988; Tyler et al. 2000). Regardless of sex, students who were directly involved in altercations as either bullies or victims were even more critical of teachers' conflict resolution skills. These findings were among the earliest to show that students scrutinize teachers' actions during conflicts, and base such judgments on personal experiences and events that they witness at schools.

Even so, it is unclear how such perceptions of teachers drive the decision making of adolescent students when faced with an incident such as victimization. Additionally, perceptions of teachers' actions during conflicts have never been examined specifically in high-risk school environments with frequent physical conflicts, where such perceptions may be even more relevant during adolescent decision making. We thus expand on previous work by examining how student perceptions of their teachers' actions during conflicts influence two potential responses to victimization (seeking help from school authority or reactive, physical aggression) in a high-risk adolescent sample.

\section{A Social Information Processing Framework of Aggression}

Social information processing models provide a useful framework for our research because they explain why aggressive responses to victimization may occur instead of seeking help from school authority. Fontaine and Dodge (2006) have recently proposed a Response Evaluation and Decision (RED) model that outlines how youth decide on executing aggressive vs. non-aggressive behaviors in hostile situations (see also Fontaine 2008). This model, which argues that a comparative evaluation of multiple, alternative responses to peer provocation occur prior to an actual enactment of behavior, has been empirically validated in recent studies with youth (Fontaine et al. 2008). We propose that one source of information entering the response decision phase may be a student's perceptions of teacher effectiveness during interventions related to student conflict and victimization. Because of our interest in how these perceptions influence adolescent responses, we focus on aggression that is reactive in nature as an outcome to events such as victimization.

Along these lines, aggression researchers have suggested that, when provoked, reactively aggressive youth show deficits in generating non-aggressive response options (Fontaine and Dodge 2006; Huesmann 1988). Although social information processing deficits have been cited as underlying reactively aggressive behavior (e.g., Dodge and Coie 1987), other evidence suggests that some forms of reactive aggression may be an adaptation to environments in which there are few effective alternatives to aggressive behavior (Herzberger and Hall 1993; McClowskey et al. 2005; Rogers and Tisak 1996). For example, McClowskey et al. (2005), demonstrated that when under aggressive provocation (i.e., having points stolen by a computer generated opponent), participants were likely to retaliate using aggressive point subtraction against their hypothetical opponents. However, aggressive retaliation was significantly reduced when participants were given an escape option that effectively safeguarded them against point loss. When applied to adolescents in real world settings, these findings suggest environments providing few alternative options for responding to aggressive peers may encourage levels of reactive aggression-as either a forced self defense or retaliation. These environments include schools in which teachers have failed to demonstrate the ability to manage conflict, thereby rendering school authority as an ineffective source of support for dealing with violence and victimization. As such, perceptions of teachers' abilities to address school conflict should have an influence on student's decisions to respond violently to victimization.

A number of variables other than perceptions of teachers have also been shown to predict adolescent responses to victimization, and whether they will turn to teachers for assistance in resolving conflicts. These include normative beliefs about aggression, previous levels of aggressive behavior, and student-teacher relationship quality (Erdley and Asher 1998; Huesmann and Guerra 1997; Meehan et al. 2003). Students who believe aggression is acceptable, who have a history of aggressive behavioral problems, and who do not get along with teachers may find it difficult to turn to school authority and refrain from aggressive responses when faced by an aggressive, victimizing peer. Controlling for these variables is thus necessary to determine whether perceptions of teachers' actions during conflicts plays a unique role in encouraging help seeking 
responses and in discouraging aggressive behavior when victimized.

When responding to victimization, boys and girls differ in their tendency to react with violence (Dodge et al. 2006). These differences may be related to the way in which events such as victimization influence the cognitive processing of each sex. For example, Mrug et al. (2008) found that adolescent boys (but not girls) experienced increases in aggressive cognitions following exposure to violence. Thus, we expect boys to deal with victimization in aggressive ways. However, sex differences in tendencies to turn to teachers when victimized are less clear. Rigby and Bagshaw (2003) found that sex did not predict adolescent perceptions of teachers' actions during conflicts, although a greater portion of their female sample entertained the prospects of working with teachers to resolve bullying. Collectively, these studies suggest that girls may be less prone to reactive aggression and more inclined to turn to teachers when victimized.

\section{The Present Study}

Vignettes were used for the current study because they allow standardization of victimization events, provoke responses that reflect social information processing, and demonstrate predictive-behavioral validity among youth (e.g., Bellmore et al. 2005; Dirks et al. 2007; Dodge et al. 2002; Fontaine et al. 2002, 2008; Fontaine 2006). For example, Bellmore et al. (2005) found that hostile responses to vignettes predicted peer and teacher rated aggressive behavior in the classroom. Thus, there is both theoretical and empirical basis for the use of vignettes in the current study.

We hypothesize that when students perceive teachers as effective in addressing conflicts, these students are more likely to seek help from school authority when victimized. In line with concepts of decision making processes and aggression (Bellmore et al. 2005; Fontaine and Dodge 2006; Huesmann 1988), we further predict that students who are more willing to seek help from school authority will consequently be less inclined to react aggressively during the same victimization scenario. As such, when presented with victimization vignettes, adolescent students' likelihood of reacting aggressively will be indirectly influenced by their perceptions of teachers' actions during conflicts (through the direct effect of seeking help from school authority).

Second, we hypothesize that boys will be less likely to seek help from school authority and more inclined to react aggressively when victimized (e.g., Dodge et al. 2006; Mrug et al. 2008). Despite the aggressive tendencies of boys, we expect that teachers' actions during conflicts will still have an effect for both male and female adolescents responding to victimization vignettes. Last, we predict that although covariates such as normative beliefs about aggression, previous aggressive behavior, and studentteacher relationship quality may influence how students respond to victimization vignettes, the inclusion of such covariates into a predictive model of victimization response will not mitigate the effects of student perceptions of teachers' actions during conflicts.

\section{Method}

Recruitment and Procedure

\section{Participants and Setting}

Participants were 148 adolescents from a high school located in an urban, low-income community on the U.S. West Coast. We approached this sample following an invitation from the school's principal, who voiced concern about the violence and victimization occurring on school grounds prior to the study. A subsample of 136 students from the high school completed victimization questionnaires on the day of the study to confirm this report. The remaining 12 students provided incomplete or missing data on this portion of the survey. Fifty-two percent of the 136 students who participated reported both experiencing and witnessing at least one form of physical victimization, $37.5 \%$ reported only witnessing victimization, and $10.5 \%$ of participants reported no experience or witnessing of physical victimization on school grounds since the start of the school year. Despite the latter $10.5 \%$, all students in the sample were able to recall observing an incident of victimization when completing open-ended portions of the survey. The average number of experienced physical victimization incidents was $1.95(\mathrm{SD}=2.93)$, and students reported witnessing $4.16(\mathrm{SD}=2.95)$ events on average since the start of the school year.

Of the 148 students, $49.3 \%(n=73)$ were female. Thirty-seven percent $(n=54)$ were in the 9 th grade, $23 \%$ $(n=34)$ were in 10 th, $20 \%(n=30)$ were in 11 th, and $20 \%$ ( $n=30)$ were in 12th grade. School records classified $51.5 \%(n=76)$ of the sample as Latino, $24.2 \%(n=36)$ as Asian American, $18.9 \%(n=28)$ as African American, and $5.3 \%(n=8)$ as other, including students who were Caucasian, Middle Eastern, or mixed ethnicity. The high number of ethnic minorities was representative of the school and surrounding neighborhood. The school employs a monolingual course curriculum, and all students have working knowledge of the English language. Questionnaires were thus printed in English, and there were no reports of language comprehension issues or problems during the course of the study. 


\section{Procedure}

Passive consent forms were distributed to parents 2 weeks before the study. Parents were given the option to refuse their child's right to participate by returning the passive consent form or by contacting the investigator, principal, or teachers. The investigators and school did not receive any forms or notification from parents indicating that their child should not be included in the study.

Surveys were distributed to students 3.5 months into the first semester of the 2006-2007 school year. Prior to the survey's distribution, teachers presented students with consent forms that explained the survey and its voluntary nature. Students who agreed to participate signed the consent and were given a survey packet by their homeroom teachers. The surveys were administered by the same homeroom teacher over 2 consecutive days. Once the survey was completed, the lead investigator retrieved the surveys that were sealed in boxes by each homeroom teacher.

At the time of the survey, 313 students were enrolled in the school. However, student absences were quite common, and on the day of the survey only 238 students were present. One hundred ninety-seven students turned in surveys with valid responses. Of the 197 surveys we collected, 49 students who completed the main component of the survey did not take part in completing the victimization scenario vignettes. Once we performed a listwise deletion of these 49 cases with missing victimization scenario data, a working sample of 148 students remained. $T$-tests revealed no significant difference between the final working sample and the dropped cases for sex, grade level, ethnicity, aggression, student-teacher relationship quality, and perceptions of teachers' actions during conflicts variables listed below (all $t$ ' $s<1$ ).

\section{Measures}

\section{Reactive and Proactive Aggression (RPQ)}

The reactive-proactive aggression questionnaire (RPQ; Raine et al. 2006) is a 21-item self-report measure of aggression. Items on the RPQ are answered on a threepoint scale measuring how often an individual engages in a specific aggressive behavior, with 0 indicating never, 1 indicating sometimes, and 2 indicating often. This scale has a two-factor structure, with 11 items tapping reactive aggression (e.g., How often have you reacted angrily when provoked by others?) and 12 measuring proactive aggression (e.g., How often have you used force to obtain money or things from others). Each subscale has demonstrated good internal reliability and has been validated with an adolescent sample (Raine et al. 2006).
Reactive and proactive scores are derived by summing the 11 and 12 items, respectively. In the current sample, the reactive $(M=8.37, \mathrm{SD}=5.11, \alpha=.86)$, and proactive $(M=3.62, \mathrm{SD}=4.60, \alpha=.89)$ subscales demonstrated good reliability and were highly correlated, $r(148)=.69$, $p<.001$. Indicative of the at-risk nature of the sample, the overall mean scores for the subscales were higher in this study than in previous publications (Raine et al. 2006).

\section{Beliefs About Aggression}

We measured participants' beliefs about the acceptability of aggression to account for social information processing that predicts aggressive behavior among youth. Given time constraints, we adapted 6 items from previous measures to assess adolescent beliefs about the acceptability of aggression (see Erdley and Asher 1998; Huesmann and Guerra 1997). Items measured student beliefs about the acceptability of aggression in general (It's ok for two students to fight each other; When two students are fighting each other, it's okay to cheer for them), reactive or retaliatory aggression (It's important for students to show they are ready to fight anyone who picks on them), and instrumental aggression (e.g., Students get what they want from other students by fighting with them). Responses for these items ranged from 1 (don't agree at all) to 4 (completely agree) and demonstrated good reliability. We averaged them to form a beliefs about aggression score for each participant $(M=1.77, \mathrm{SD}=.72, \alpha=.82)$.

\section{Student-Teacher Relationship Quality}

As a general indicator of student-teacher relationship quality, we used scores from the Trust In and Respect for Teachers Scale (Battistich et al. 2004). This measure is a 10-item questionnaire assessing student appraisals of teachers and relationship quality. Respondents answer on a five-point likert scale ranging from 1 (not at all true), to 5 (very true) to indicate their agreement with each statement. Example statements included The teachers at this school really care about me, The teachers here always try to be fair, and I feel safe and comfortable with teachers at this school. This measure allowed us to examine whether student perceptions of teachers' actions during conflicts predicted scenario responses over and above this more general appraisal of student-teacher relationship quality $(M=3.19$, $\mathrm{SD}=.94, \alpha=.76)$.

Student Perceptions of Teachers' Actions During Conflicts (TAC)

Perceptions of TAC were measured using nine items related to the fairness, justice, and outcome success of 
Table 1 Items measuring student perceptions of teachers actions during conflicts (TAC)

Measure items

$M$

$\mathrm{SD}$

General conflict items

1. How satisfied are you with the procedures teachers use to resolve student disputes (such as arguments, fights)?

$3.04 \quad .93$

2. How satisfied are you with the outcomes of student disputes (such as arguments or fights) when teachers get involved?

$2.97 \quad .93$

3. How much would you trust the teachers at the [high school] to resolve a future student dispute?

$3.12 \quad 1.05$

4. How effective are teachers and the administration at preventing fights between students?

$2.78 \quad 1.02$

5. How often are the teachers successful in stopping fights between students?

$2.79 \quad 1.10$

Incident specific- victimization items

6. How satisfied were you with the procedures the teacher(s) used to resolve the conflict?

$2.90 \quad .83$

7. How satisfied were you with the outcomes of the conflict, after the teachers stepped in?

$2.95 \quad .88$

8. How good were the teachers at stopping the conflict when it happened?

$2.78 \quad .96$

9. How good were the teachers at stopping the conflict from happening again in the future?

$2.74 \quad 1.01$

teachers' interventions during student conflicts. TAC items were similar to those used by Rigby and Bagshaw (2003), who measured dimensions including perceived conflict resolution skills of teachers, perceived helpfulness of teachers, and perceived fair treatment by teachers. Five of the current items tapped student perceptions of TAC in general at the school; the remaining four assessed views regarding a specific, recalled victimization event in which a teacher attempted to resolve the problem (see Table 1). These nine items were averaged to form a measure of perceptions of TAC $(M=2.89, \mathrm{SD}=.67, \alpha=.86)$.

\section{Victimization Vignettes}

Two victimization scenarios were described in a brief sentence to assess how adolescents would respond to being victimized by an aggressive peer. The instructions preceding each scenario read as follows: Sometimes, high school students are victims of a peer's actions. For example, some high school students get picked on, are bullied, and others are hit or threatened. We would like to know how you would respond to such events when they happen at your school.

The first scenario described an event of minor victimization, or peer harassment: "Imagine another student is making fun of you and pushing you around the halls all the time". This scenario was selected as an event of minor victimization, conforming to definitions of bullying or peer victimization (Olweus 2001). The second described a more severe incident of violent victimization involving a weapon: "Imagine another student is being very violent with you (for example, threatening you with a weapon), and you think your life may be in danger". This incident was adapted from items that have been used in previous adolescent surveys to assess experiences of violent victimization (e.g., Aceves and Cookston 2007; Finkelhor et al. 2005). Participants read and responded to both scenarios sequentially. Our intention was to ultimately average the responses across the minor and violent victimization scenarios. ${ }^{1}$

Participants responded to each scenario by indicating how likely they would react in one of nine ways, including ignoring the problem, verbally talking back, seeking help from peers, seeking help from parents, seeking help from police, physically fighting back, or seeking support from three sources of school authority: teachers, school counselors, and the school's principal. These items were not exclusive, and participants provided responses to all nine items following each victimization prompt. Given the nature of our study, we only conducted analyses using the seeking help from school authority and physical aggression responses. ${ }^{2}$ These items read as follows: I would deal with the student doing these things to me by confronting them physically (fight back), I would tell a teacher about the situation, I would tell my principal about the situation, and I would tell my school counselor about the situation. Participants responded to these items using a 1-4 likert scale, ranging from completely disagreeing (1) to completely agreeing (4) with each presented statement.

To measure the likelihood of reacting aggressively to the scenario, we averaged the fighting back response across the minor and violent victimization scenarios $(M=2.48$, $\mathrm{SD}=.87, \alpha=.67)$; the resulting aggressive response score

\footnotetext{
${ }^{1}$ We should note that a general linear model confirmed a repeated measures main effect of victimization scenario severity. However, there was no interaction with victimization severity and perceptions of TAC, suggesting the pattern of relationships between the variables of interest in the hypothesized model was the same across scenarios. Accordingly, we collapsed responses across the two victimization scenarios. Additional data regarding the effect of victimization severity can be requested from the first author.

2 Descriptive and correlational data from all nine response options are not reported further in this paper. Separate analyses from the individual response items are available upon request from the first author.
} 
Table 2 Correlations among study variables

\begin{tabular}{|c|c|c|c|c|c|c|c|c|c|}
\hline Variable & 1. & 2. & 3. & 4. & 5. & 6. & 7. & 8. & 9. \\
\hline 1. Sex & - & & & & & & & & \\
\hline 2. Class year & .02 & - & & & & & & & \\
\hline 3. Student perceptions of TAC & .02 & .04 & - & & & & & & \\
\hline 4. Trust and respect for teachers & .03 & $.15^{\dagger}$ & $.63 * * *$ & - & & & & & \\
\hline 5. Beliefs about aggression & $.24 * *$ & -.06 & $-.20^{*}$ & $-.35 * * *$ & - & & & & \\
\hline 6. Proactive aggression (RPQ) & $.15^{\dagger}$ & -.01 & -.07 & $-.27 * *$ & $.56 * * *$ & - & & & \\
\hline 7. Reactive aggression (RPQ) & -.02 & -.10 & $-.26 * *$ & $-.35 * * *$ & $.46^{* * *}$ & $.69 * * *$ & - & & \\
\hline 8. Victimization scenario: SA & $-.17 *$ & -.04 & $.42 * * *$ & $.33 * * *$ & $-.27 * *$ & -.12 & $-.19 *$ & - & \\
\hline 9. Victimization scenario: FB & $.27 * *$ & -.04 & $-.24 * *$ & $-.35 * * *$ & $.51 * *$ & $.37 * * *$ & $.41 * * *$ & $-.38 * * *$ & - \\
\hline
\end{tabular}

Note: $S A$ seek school authority help, FB fight back- both responses made in their respective victimization scenarios

${ }^{\dagger} p<.10 ; * p<.05 ; * * p<.01 ; * * * p<.001$

was normally distributed. Seeking help from school authority was measured as willingness to inform a teacher, principal, or school counselor about the victimization incident in both minor and violent scenarios. These six items ( 3 for the minor scenario items and 3 for the violent scenario items) were averaged to form a normally distributed measure of willingness to seek help from school authority when victimized $(M=2.35, \mathrm{SD}=.88, \alpha=.93) .^{3}$

\section{Results}

\section{Data Analysis Plan}

We first explored descriptive, comparative, and correlational statistics related to the student perceptions of TAC measure, in order to help understand the nature of this construct (see Table 2). ${ }^{4}$ Next, multiple regression was used to examine whether sex moderates the relationship

\footnotetext{
${ }^{3}$ We thank an anonymous reviewer for pointing out that by averaging these three items, a bias may be created for the neutral of the three responses. To address this, we conducted the path analyses described below using only the maximum of the three seeking help items from each scenario. The results of these single item analyses were not significantly different from the path analysis we report below.

${ }^{4}$ To explore possible ethnic and sex differences in perceptions of TAC, we conducted a $2(\operatorname{sex}) \times 3$ (ethnicity: Latino, Black, Asian) between subjects ANOVA. There were no significant sex or race differences in students' perceptions of TAC scores (main effect and interaction $\mathrm{Fs}<1$ ), indicating no systematic variability in how adolescents viewed teachers' abilities to resolve conflicts based on race or sex.

Reactive aggression scores on the RPQ were significantly and negatively correlated with TAC $(r=-.26, p<.002)$ but proactive aggression scores were not $(r=-.07, p=.38)$. TAC was positively correlated with theoretically expected measures, including trust in and respect for teachers $(r=.63, p<.001)$, and seeking help from school authority in the victimization scenarios $(r=.42, p<.001)$; it was negatively correlated with fighting back as a response to the victimization scenarios $(r=-.38, p<.001)$.
}

between perceptions of TAC and responses to the victimization scenarios. Last, to test the hypotheses that students' perceptions of TAC (a) increase willingness to seek help from school authority when victimized and consequently (b) reduce the likelihood of responding aggressively, we tested an indirect effect using covariance structure modeling with measured variables (i.e., path analysis).

\section{Testing Sex as a Moderating Variable}

We used multiple regression to determine whether sex and perceptions of TAC interacted to predict seeking help or fighting back responses in the victimization scenarios. Two separate regressions were modeled in which the dependent variables were either seeking help from school authority or fighting back in response to the victimization scenarios. The variables of student-teacher relationship quality, beliefs about aggression, reactive aggression, and proactive aggression were entered as covariates into the regressions. Sex and perceptions of TAC were entered next into both regressions, followed by a sex $\times$ perceptions of TAC interaction term. The results indicated that sex did not interact with perceptions of TAC when predicting help seeking $(\beta=.08, p=.80)$ and fighting back responses ( $\beta=-.22, p=.48)$ to the victimization scenarios. There were, however, main effects for sex and perceptions of TAC as predictors individually. As a result, we retained sex as a covariate in subsequent analyses (see Table 3).

\section{Test of an Indirect Effect}

To test the hypothesis that perceptions of TAC predict seeking help from school authority, and in turn negatively predict aggressive responses to victimization, we used path analysis following recommendations for testing an indirect effect with covariance structure models (Bellmore et al. 2005; Holmbeck 1997; Hoyle and Smith 1994). Analyses were conducted using maximum likelihood estimation in 
Table 3 Multiple regressions predicting help seeking and aggressive responses to victimization scenarios

\begin{tabular}{|c|c|c|c|c|c|c|c|c|}
\hline \multirow[t]{2}{*}{ Predictors } & \multicolumn{4}{|c|}{ Criterion: seek help from school authority } & \multicolumn{4}{|c|}{ Criterion: fight back } \\
\hline & $B$ & SE & $\beta$ & $t$ & $B$ & SE & $\beta$ & $t$ \\
\hline \multicolumn{9}{|l|}{ Covariates } \\
\hline 1. Trust in teachers & .11 & .14 & .08 & .76 & -.21 & .13 & -.16 & -1.69 \\
\hline 2. Beliefs about aggression & -.18 & .12 & -.15 & -1.58 & .37 & .10 & .31 & $3.60 * * *$ \\
\hline 3. Reactive aggression & -.01 & .02 & -.06 & .53 & .04 & .02 & .23 & $2.35^{*}$ \\
\hline 4. Proactive aggression & .01 & .02 & .07 & .60 & -.01 & .02 & -.04 & -.40 \\
\hline \multicolumn{9}{|l|}{ Independent variables } \\
\hline 5. Sex & -.13 & .07 & -.15 & $-1.95^{\dagger}$ & .19 & .06 & .22 & $3.04 * *$ \\
\hline 6. Perceptions of TAC & .29 & .09 & .33 & $3.41 * *$ & -.03 & .08 & -.03 & -.33 \\
\hline
\end{tabular}

${ }^{\dagger} p<.053 ; * p<.05, * * p<.01, * * * p<.001$

AMOS, version 16. We evaluated model fit according to guidelines proposed by $\mathrm{Hu}$ and Bentler (1999).

In the path analysis, the key independent variable was student perceptions of TAC. The dependent variable was the likelihood that the participant would choose to physically fight back in response to victimization, averaged across the minor and violent victimization scenarios. Perceptions of TAC were hypothesized to indirectly have a negative effect on the dependent variable (i.e., higher perceptions of TAC would reduce the likelihood of fighting back), though indirectly through the seeking help response variable (i.e., seeking help from a teacher, principal, or counselor). Thus, the path analysis evaluates the contention that perceptions of TAC lead to an increased likelihood of seeking help from school authority when victimized, which in turn reduces the likelihood of responding to victimization by aggressively fighting back.

We first report a path analysis that tests our indirect effect hypothesis, and then conduct additional analyses to provide further validation for the hypothesized model. These additional analyses include the testing of alternative hypotheses (e.g., that perceptions of TAC predict fighting back when victimized, which in turn predicts seeking help from school authority), which, if true, would counter our claims. Thus, any alternative path analysis should demonstrate a worse fit than our primary, hypothesized indirect effect model. Last, we perform a final path analysis with inclusion of the aforementioned covariates to test the hypothesis that TAC's indirect effect on fighting back is not affected when accounting for the effects of normative beliefs about aggression, previous aggressive behavior, student-teacher relationship quality, and sex.

\section{Testing the Direct Effect}

Perceptions of TAC were significantly associated with fighting back in the victimization scenarios. Adolescents who reported positive perceptions of TAC were less likely to report fighting back as a response to victimization $(\beta=-.24, p<.01)$. Because the direct effect model is saturated, the fit estimates are redundant and fail to provide meaningful information, with the exception of an RMSEA of .23 .

\section{Testing the Hypothesized Indirect Effect}

We next tested the hypothesized indirect effect model, in which perceptions of TAC were expected to influence a greater willingness to seek help from school authority, and in turn reduce the likelihood of fighting back. Following statistical recommendations (Holmbeck 1997), we constrained the path from perceptions of TAC and fighting back to 0 . We estimated path coefficients from perceptions of TAC to seeking help from school authority, and from seeking help from school authority to fighting back. The overall model fit the data well, $\chi^{2}(1, N=148)=1.55, p>.21$; RMSEA $=$ .06 ; GFI $=.99$; RMR $=.02$; see Hu and Bentler 1999). Perceptions of TAC significantly predicted seeking help from school authority $(\beta=.42, p<.001)$, and seeking help from school authority was negatively associated with fighting back ( $\beta=-.38, p<.001$; see Fig. 1$)$.

Next, we tested the fit of an additional model in which the path between TAC and fighting back was allowed to vary. An indirect effect is demonstrated if this non-constrained model does not improve the statistical fit. In line with our hypothesis, when the path from perceptions of TAC to fighting back was free to vary, the statistical fit did not improve. Specifically, the RMSEA worsened from .06 to .33 , indicating that the hypothesized indirect effect model fit the data better.

A comparison of the standardized path coefficients provides further illustration of the indirect effect that perceptions of TAC have on fighting back when victimized. In the simple direct effect model, the standardized coefficient for the TAC $\rightarrow$ Fighting back path was $-.24, p<.01$. When seeking help from school authority was introduced 


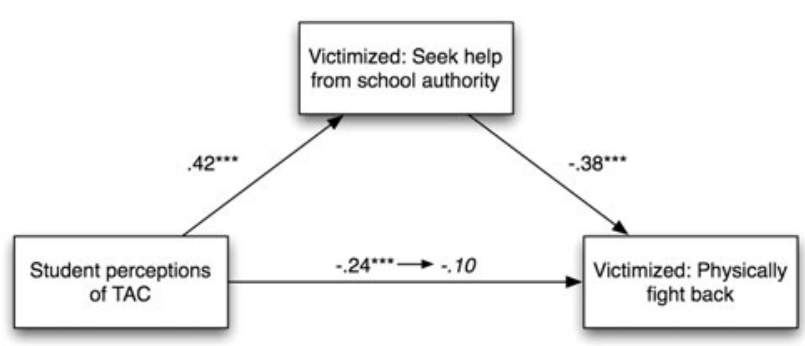

Fig. 1 Indirect effect model: fighting back in victimization scenarios is indirectly influenced by perceptions of TAC

into the model as in Fig. 1, the same path coefficient was reduced to non-significance $(\beta-.10, p=.21)$. Although these results confirmed the indirect effect hypothesis, we performed the additional statistical tests described below to further validate the results.

\section{Alternative Models}

To further scrutinize the hypothesized indirect effect model, we followed the empirical example of Bellmore et al. (2005) and examined the fit and path coefficients of two alternative models. Models in which perceptions of TAC served as an intermediary or dependent variable were not tested because the TAC construct is measured as a cognitive schema (see Huesmann 1988), intended to tap adolescents' perceptions of teachers' actions from past conflicts at the school. Thus, models where TAC was an outcome of scenario responses were not theoretically plausible (see for example Bellmore et al. 2005).

We first tested the alternative hypothesis that perceptions of TAC lead to lower levels of fighting back, which in turn is negatively associated with seeking school authority help (i.e., the intermediary and dependent variable of the hypothesized model were switched). The second alternative model examined perceptions of TAC as the independent variable, with two concurrent paths predicting seeking help from school authority and fighting back (i.e., two dependent variables) with no indirect effect modeled. Fit indices and path coefficients for these two alternative models are presented in Table 4. Each alternative model demonstrated worse fit when compared to the indirect effect model, further supporting our core hypothesis.

Last, we sought to determine if perceptions of TAC maintained a significant relationship to seeking help from school authority, and an indirect effect on fighting back, after controlling for covariates and sex. Sex, student-teacher relationship quality, proactive and reactive aggression, and beliefs about aggression were entered as endogenous measured variables in the indirect effect model. Paths were drawn from the covariates to seeking help from school authority, and the dependent variable fighting back. Each control variable was allowed to co-vary with one another and perceptions of TAC.

Initially, each covariate was modeled with non-constrained paths to seeking help from school authority and fighting back. This model revealed that student-teacher relationship quality and proactive aggression were not associated with seeking help from school authority or fighting back; they were thus dropped from the model. Paths from beliefs about aggression and reactive aggression to seeking help from school authority were also not significant; we trimmed them as well. We retained the remaining significant covariate paths, and the resulting parsimonious covariate model fit the data well $\left(\chi^{2}[3\right.$, $N=148]=4.47, \quad p>.21, \quad R M S E A=.06, \quad G F I=.99$, $R M R=.08 ;$ see Table 4).

As predicted, inclusion of reactive aggression, beliefs about aggression, and student-teacher relationship quality as covariates did not affect the indirect influence of perceptions of TAC on fighting back in the victimization scenarios. This more parsimonious model that includes sex, beliefs about aggression, and reactive aggression as exogenous predictors also provides a more detailed account of the factors that may contribute to seeking help from school authority and fighting back in response to victimization.

\section{Discussion}

Data supported the hypothesis that adolescents who view teachers as effective and fair in resolving conflicts are more likely to consider turning to school authority during victimization scenarios, and are consequently less likely to consider physical aggression as a response. Compared to girls, boys were less likely to seek help from school authority and more likely to report physical aggression as a favorable response across victimization scenarios. Furthermore, although the covariates of beliefs about aggression, reactive aggressive behaviors, and male status predicted fighting back in the victimization scenarios, willingness to seek help from school authority continued to indirectly link perceptions of TAC and fighting back even when these covariates were controlled. The results provide support for our contention that teachers' actions during conflicts (when perceived positively) encourages students to turn to teachers when victimized, which may reduce students' subsequent aggressive actions.

These findings add to a well supported literature demonstrating that boys are more physically aggressive than girls (Dodge et al. 2006). However, they also provide encouraging evidence that positive perceptions of teachers' actions during conflicts may influence adolescents to respond to victimization with less violent means, regardless of sex. Yet, with male status serving as a predictor of the 
Table 4 Fit indices and path coefficients of path analysis models

\begin{tabular}{|c|c|c|c|c|c|c|c|}
\hline \multirow[t]{2}{*}{ Model and paths } & \multicolumn{7}{|c|}{ Path coefficients and fit indices } \\
\hline & $B$ & SE & $\beta$ & $\chi^{2}$ & RMSEA & GFI & RMR \\
\hline 1. Direct effect model & -.32 & .10 & -.24 & 0 & .32 & 1.00 & .00 \\
\hline 2. Hypothesized mediation model & & & & 1.55 & .06 & .99 & .02 \\
\hline TAC $\rightarrow$ SA help & .55 & .10 & $.42 * * *$ & & & & \\
\hline SA help $\rightarrow$ fight back & -.37 & .08 & $-.38 * * *$ & & & & \\
\hline 3. Alternative model A & & & & $15.13 * * *$ & .31 & .94 & .08 \\
\hline TAC $\rightarrow$ SA help & .55 & .10 & $.42 * * *$ & & & & \\
\hline TAC $\rightarrow$ fight back & -.32 & .10 & $-.24 * * *$ & & & & \\
\hline 4. Alternative model B & & & & $20.8 * * *$ & .36 & .92 & .07 \\
\hline TAC $\rightarrow$ fight back & -.32 & .10 & $-.24 * * *$ & & & & \\
\hline Fight back $\rightarrow$ SA help & -.38 & .07 & $-.38 * * *$ & & & & \\
\hline 5. Covariate mediation model & & & & 4.47 & .06 & .99 & .08 \\
\hline TAC $\rightarrow$ SA help & .55 & .12 & $.42 * * *$ & & & & \\
\hline Sex $\rightarrow$ SA help & -.30 & .13 & $-.17 *$ & & & & \\
\hline Sex $\rightarrow$ fight back & .29 & .11 & $.17 *$ & & & & \\
\hline Beliefs about aggression $\rightarrow$ fight back & .36 & .09 & $.31 * * *$ & & & & \\
\hline Reactive aggression $\rightarrow$ fight back & .36 & .01 & $.23 * *$ & & & & \\
\hline SA help $\rightarrow$ fight back & -.22 & .07 & $-.23 * * *$ & & & & \\
\hline
\end{tabular}

Note: TAC student perceptions of teachers' actions during conflicts, SA help seeking help from school authority

$* p<.05 ; * * p<.01 ; * * * p<.001$

fighting back response, even in violent scenarios, concern over boys is particularly warranted. Determining ways to promote adolescent boys' willingness to turn to school authority rather than to fight back is of interest for future research in this area.

Increasing the likelihood that youth will turn to school authority when confronted or victimized is in the best interest of school communities for a number of reasons. First, the option of turning to an effective school authority may provide relief not only from victimization but also from the feelings of isolation, rejection, and hopelessness that victims tend to experience (Hinton-Nelson et al. 1996; Juvonen et al. 2000; Prinstein et al. 2001). Second, as our data suggest, adolescents who perceive that teachers can effectively address conflict and victimization may be less inclined to resort to aggression, which carries implications for decreasing over-all levels of school violence. Third, in violent life-threatening situations involving weapons, turning to adults for help may be a safer choice than responses that escalate aggression and potentially lead to serious injury.

Having the option to turn to school authority, though ideal, may not always be realistic for adolescents during hostile conflicts. On one hand, violent events can take place away from the supervision of school authority, placing victims away from potential, immediate support sources while at school. However, our findings may still be relevant in such situations. Although turning to a teacher who is in close proximity may not always be an immediate option, perceiving teachers as effective for dealing with conflicts may prevent retaliatory aggression well after the victimization has taken place. In this sense, positive perceptions of teachers' abilities to manage conflicts can make the difference between a victimized student who goes home, evaluates the incident, and turns to teachers for help the following day, as opposed to one who returns to school with a weapon to retaliate.

The variance of the TAC measure suggests student perceptions differ despite their attending the same school environment, though how can this variability be explained? Rigby and Bagshaw (2003) found that student reports of teachers' ability to manage conflict differed based on their own social roles as bullies, victims, or bystanders. Our statistical control of aggression variables (i.e., proactive aggression) that correlate with bullying behaviors suggests that such potential individual differences were not meaningfully linked to perceptions of teachers' abilities in the present report. Still, the distribution of student perceptions of teachers' actions during conflicts could reveal that some teachers are inconsistent in their skills and success during conflict resolution. Alternatively, the within-school variability may indicate individual differences between teachers and their abilities to manage conflict. Variance across cohorts of teachers and their attitudes towards bullying has been noted in other studies (Bauman and Del Rio 2006), and merits a deeper investigation of why perceptions of TAC differ in single, as well as multi-school samples. 
Although general student-teacher relationship quality was correlated with perceptions of teachers' actions during conflict, we found that the TAC construct was uniquely associated with how students responded to the victimization scenarios. That is, the association in Fig. 1 was supported, above and beyond the effect of general student-teacher relationship quality. We argue that, in addition to promoting positive student-teacher relationships, teachers should be trained in and commit to mastering effective conflict resolution in order to increase the likelihood that students will turn to school authority in times of need, and potentially reduce incidents of reactive aggression.

\section{Understanding Reactive Aggression through Social Information Processing Models}

As suspected, perceptions of teachers' actions during conflicts negatively correlated with reactive aggression but not proactive aggression. This finding is in line with theory suggesting that reactively aggressive youth have relatively few mental scripts or response options when reacting to aggressive provocation (Crick and Dodge 1996; Fontaine and Dodge 2006; Huesman 1988). Yet, having fewer response options may be a product of situational or environmental factors (e.g., McClowskey et al. 2005). Our findings suggest that, in some cases, reactive aggression could potentially be adaptive in the context of a hostile school environment with unsupportive teachers. In these high-risk environments, self defensive aggression could be one of the only ways to safeguard oneself from harmful peers, especially when the school authority is unable to ensure student safety.

At the social information processing level (Crick and Dodge 1994; Fontaine and Dodge 2006; Huesmann 1988), these findings highlight how alternative responses to aggression in the face of provocation or victimization can be encouraged by modeling effective teacher interventions. Effective teachers provide adolescent students with alternative, non-aggressive options for dealing with aggressive peers and victimization. Relating to the findings of McClowskey et al. (2005), effective teachers may serve as an escape option, or alternative to retaliation. Our findings mirror these previous aggression paradigm data, demonstrating that, in victimization scenarios, reactive aggression may sometimes result from the lack of an equally effective and alternative option for responding to provocation.

There are a number of reasons why proactive aggression was not considered as an outcome of perceptions of TAC. Theoretically, proactive aggression is a poor fit as a dependent variable in the path model of the current study. For example, a student with bullying intentions is arguably unlikely to turn to a teacher, prior to enacting proactively aggressive behavior. Additionally, our correlational data did not support links between perceptions of TAC and proactive aggression. However, links may be found in specific situations, such as when students hesitate to bully peers because they perceive teachers as being effective at intervening, and thus restrain bullying behaviors for fear of repercussions. Further research is needed to confirm whether links between perceptions of TAC and proactive aggression are unlikely, or can only be found in unique situations.

\section{Study Limitations}

This work was a preliminary effort to uncover the effects of a rarely investigated student perception, and consequently, there are a number of methodological limitations. First, the number of victimization scenarios and the amount of information provided in each prompt were limited due to time constraints. As a result, certain features of victimization, such as explicit power asymmetry (see Olweus 2001), may not have been interpreted equally by all students when reading the vignettes. For example, the more aggressive students may have interpreted the scenarios differently than those with less aggressive and inhibited dispositions. This can be addressed in future research by further manipulating vignette prompts for clarity, and probing adolescent interpretation of each victimization event.

An additional issue arises when applying these findings to actual rates of school aggression and violence. All data were subject to self-report methodological limitations (see Ladd and Kochenderfer-Ladd 2002). Because responses were hypothetical reactions to vignettes, and not actual behaviors, it is unclear whether student perceptions of TAC ultimately predict student-teacher interactions and lower rates of aggressive behavior on school grounds. However, adolescent studies have linked aggressive vignette responses to aggressive behavior (e.g., Bellmore et al. 2005; Dirks et al. 2007; Dodge et al. 2002; Fontaine et al. 2002, 2008; Fontaine 2006), supporting the possible application of these findings to actual levels of school violence. A more comprehensive multi-method, multi-measure assessment is necessary in order to fully capture the extent to which perceptions of TAC affect student behaviors.

Although research with underrepresented populations helps to expand adolescence literature, the characteristics of the present sample limit the generalizability of our findings. First, the sample was small, and was subject to missing data limitations. The high-school was located in a low income, urban community, and students were mostly of Latino, African American, and Asian American decent. Although we have argued that perceptions of TAC are particularly relevant in these high conflict settings, it is unclear how such perceptions develop and function in positive school environments that give rise to few student 
conflicts. Our work should be expanded to more representative and larger adolescent samples, prior to generalizing the importance of teachers' actions during conflicts for adolescent well-being.

Finally, although our hypothesized model suggested directional influences, the data are correlational and do not establish causality. We again emphasize that these data are a preliminary examination of how perceptions of teachers' actions during conflicts affect adolescent responses to hostile situations, and our intention was to promote interest on an otherwise under-researched topic. Additional research is needed to support the suggested causality derived from these findings.

\section{Conclusion}

This study contributes to the adolescence literature by demonstrating how perceptions of teachers' actions during conflicts can influence student reactions to victimization. To date, we are unaware of previous studies that have examined how these perceptions are important for understanding decision making and behavioral responses among minority adolescents in high conflict environments. The results of this study shed light on the importance and influence that adolescent perceptions have-with implications for research and theory in the aggression, victimization, and violence areas. In light of the continuing problems with aggression, victimization, and violence in schools (Eisenbraun 2007), attention to how teachers and administrators can shape positive student perceptions of the school authority's management of conflicts is recommended.

Acknowledgments This research was funded in part by a Hornaday fellowship awarded to the first author by UC Berkeley's Greater Good Science Center. We would like to thank the efforts of the high school's Principal and teachers who made this research possible, and the valuable insight provided by UC Berkeley's Relationship and Social Cognition Lab, and Writing Workshop.

Open Access This article is distributed under the terms of the Creative Commons Attribution Noncommercial License which permits any noncommercial use, distribution, and reproduction in any medium, provided the original author(s) and source are credited.

\section{References}

Aceves, M. J., \& Cookston, J. T. (2007). Violent victimization, aggression, and parent-adolescent relations: Quality parenting as a buffer for violently victimized youth. Journal of Youth and Adolescence, 35(7), 635-647.

Battistich, V., Schaps, E., \& Wilson, N. (2004). Effects of an elementary school intervention on students' "connectedness" to school and social adjustment during middle school. The Journal of Primary Prevention, 24(3), 243-262.
Bauman, S., \& Del Rio, A. (2006). Preservice teachers' responses to bullying scenarios: Comparing physical, verbal, and relational bullying. Journal of Educational Psychology, 98(1), 219-231.

Bellmore, A. D., Witkow, M. R., Graham, S., \& Juvonen, J. (2005). From beliefs to behavior: The mediating role of hostile response selection in predicting aggression. Aggressive Behavior, 31(5), 453-472.

Bernstein, J. Y., \& Watson, M. W. (1997). Children who are targets of bullying: A victim pattern. Journal of Interpersonal Violence, 12(4), 483-498.

Crick, N. R., \& Dodge, K. A. (1994). A review and reformulation of social information- processing mechanisms in children's social adjustment. Psychological Bulletin, 115(1), 74-101.

Crick, N. R., \& Dodge, K. A. (1996). Social information-processing mechanisms in reactive and proactive aggression. Child Development, 67(3), 993-1002.

Dirks, M. A., Treat, T. A., \& Weersing, V. R. (2007). The situation specificity of youth responses to peer provocation. Journal of Clinical Child and Adolescent Psychology, 36(4), 621-628.

Dodge, K. A., \& Coie, J. D. (1987). Social-information-processing factors in reactive and proactive aggression in children's peer groups. Journal of Personality and Social Psychology, 53(6), $1146-1158$.

Dodge, K. A., Coie, J. D., \& Lynam, D. (2006). Aggression and antisocial behavior in youth. In W. Damon (Series Ed.) \& N. Eisenberg ( Vol. Ed.), Handbook of child psychology: Vol. 3. Social, emotional, and personality development (6th ed., pp. 719-788). New York: Wiley.

Dodge, K. A., Laird, R., Lochman, J. E., Zelli, A., \& The Conduct Problems Prevention Research Group. (2002). Multidimensional latent-construct analysis of children's social information processing patterns: Correlations with aggressive behavior problems. Psychological Assessment, 14(1), 60-73.

Eisenbraun, K. D. (2007). Violence in schools: Prevalence, prediction, and prevention. Aggression and Violent Behavior, 12(4), $459-469$.

Erdley, C. A., \& Asher, S. R. (1998). Linkages between children's beliefs about the legitimacy of aggression and their behavior. Social Development, 7(3), 321-339.

Finkelhor, D., Ormrod, R., Turner, H., \& Hamby, S. L. (2005). The victimization of children and youth: A comprehensive, national survey. Child Maltreatment, 10(1), 5-25.

Fontaine, R. G. (2006). Applying systems principles to models of social information processing and aggressive behavior in youth. Aggression and Violent Behavior, 11(1), 64-76.

Fontaine, R. G. (2008). On-line social decision making and antisocial behavior: Some essential but neglected issues. Clinical Psychology Review, 28(1), 17-35.

Fontaine, R. G., Burks, V. S., \& Dodge, K. A. (2002). Response decision processes and externalizing behavior problems in adolescents. Development and Psychopathology, 14(1), 107-122.

Fontaine, R. G., \& Dodge, K. A. (2006). Real-time decision making and aggressive behavior in youth: A heuristic model of response evaluation and decision (RED). Aggressive Behavior, 32(6), 604-624.

Fontaine, R. G., Yang, C., Dodge, K. A., Bates, J. E., \& Pettit, G. S. (2008). Testing an individual systems model of response evaluation and decision (RED) and antisocial behavior across adolescence. Child Development, 79(2), 462-475.

Herzberger, S. D., \& Hall, J. A. (1993). Consequences of retaliatory aggression against siblings and peers: Urban minority children's expectations. Child Development, 64(6), 1773-1785.

Hinton-Nelson, M. D., Roberts, M. C., \& Snyder, C. R. (1996). Early adolescents exposed to violence: Hope and vulnerability to victimization. American Journal of Orthopsychiatry, 66(3), 346-353. 
Holmbeck, G. N. (1997). Toward terminological, conceptual, and statistical clarity in the study of mediators and moderators: Example from the child-clinical and pediatric psychology literatures. Journal of Consulting and Clinical Psychology, 65(4), 599-610.

Hoyle, R. H., \& Smith, G. T. (1994). Formulating clinical research hypotheses as structural equation models: A conceptual overview. Journal of Consulting and Clinical Psychology, 62(3), 429-440.

Hu, L. T., \& Bentler, P. M. (1999). Cutoff criteria for fit indexes in covariance structure analysis: Conventional criteria versus new alternatives. Structural Equation Modeling, 6(1), 1-55.

Huesmann, L. R. (1988). An information processing model for the development of aggression. Aggressive Behavior, 14(1), 13-24.

Huesmann, L. R., \& Guerra, N. (1997). Children's normative beliefs about aggression and aggressive behavior. Journal of Personality and Social Psychology, 72(2), 408-419.

Juvonen, J., Nishina, A., \& Graham, S. (2000). Peer harassment, psychological adjustment, and school functioning in early adolescence. Journal of Educational Psychology, 92(2), 349-359.

Ladd, G. W., \& Kochenderfer-Ladd, B. (2002). Identifying victims of peer aggression from early to middle childhood: Analysis of cross-informant data for concordance, estimation of relational adjustment, prevalence of victimization, and characteristics of identified victims. Psychological Assessment, 14(1), 74-96.

Lind, E. A., \& Tyler, T. R. (1988). The social psychology of procedural justice. New York: Plenum Press.

McClowskey, M. S., Berman, M. E., \& Coccaro, E. F. (2005). Providing an escape option reduces retaliatory aggression. Aggressive Behavior, 31(3), 228-237.

Meehan, B. T., Hughes, J. N., \& Cavell, T. A. (2003). Teacher-student relationships as compensatory resources for aggressive children. Child Development, 74(4), 1145-1157.

Mrug, S., Loosier, P. S., \& Windle, M. (2008). Violence exposure across multiple contexts: Individual and join effects on adjustment. American Journal of Orthopsychiatry, 78(1), 70-84.

Olweus, D. (2001). Peer harassment: A critical analysis and some important issues. In J. Juvonen \& S. Graham (Eds.), Peer harassment in school: The plight of the vulnerable and victimized (pp. 3-20). New York: Guilford Press.

Prinstein, M. J., Boergers, J., \& Vernberg, E. M. (2001). Overt and relational aggression in adolescents: Social psychological adjustment of aggressors and victims. Journal of Clinical Child Psychology, 30(4), 479-491.
Raine, A., Dodge, K., Loeber, R., Gatzke-Kopp, L., Lynam, D., Reynolds, C., et al. (2006). The reactive-proactive aggression questionnaire: Differential correlates of reactive and proactive aggression in adolescent boys. Aggressive Behavior, 32(2), $159-171$.

Rigby, K., \& Bagshaw, D. (2003). Prospects of adolescent students collaborating with teachers in addressing issues of bullying and conflict in schools. Educational Psychology, 23(5), 535-546.

Rogers, M. J., \& Tisak, M. S. (1996). Children's reasoning about responses to peer aggression: Victims and witnesses expected and prescribed behaviors. Aggressive Behavior, 22(4), 259-269.

Tyler, T. R., Lind, E. A., \& Huo, Y. J. (2000). Cultural values and authority relations: The psychology of conflict resolution across cultures. Psychology, Public Policy and Law, 6(4), 1138-1163.

\section{Author Biographies}

Mario J. Aceves is a graduate student completing his Ph.D. in Psychology at the University of California at Berkeley. He received his Bachelor of Arts in Psychology from San Francisco State University, and has since been interested in Developmental Psychology research.

Stephen P. Hinshaw is Professor and Chair of the Department of Psychology at UC Berkeley. He received his doctorate in Clinical Psychology from UCLA and was a post-doctoral fellow at UC San Francisco. An expert in developmental psychopathology and mental illness stigma, he is a Fellow of the American Association for the Advancement of Science and is currently editor of Psychological Bulletin.

Rodolfo Mendoza-Denton received his Ph.D. in Social Psychology at Columbia University under the mentorship of Walter Mischel and Geraldine Downey. He remained at Columbia for post-doctoral training, and became an assistant professor at the University of California, Berkeley in 2002.

Elizabeth Page-Gould is an assistant professor at the University of Toronto Scarborough. She received her Ph.D. in psychology from the University of California, Berkeley in 2008, and has recently completed a postdoctoral fellowship at Harvard University. 